\title{
SISTEM PAKAR PENDIAGNOSA PENYAKIT MENULAR PADA ANJING
}

\author{
KADEK RISNA WITARI ${ }^{1}$, I.G.K. GANDHIADI ${ }^{2}$, \\ I Putu Eka Nila Kencana ${ }^{3}$ \\ 1, 2, 3 Jurusan Matematika FMIPA Universitas Udayana, Bukit Jimbaran-Bali, \\ e-mail: ${ }^{1}$ risna_witari@yahoo.com \\ 22gandhiadi@math.unud.ac.id, 3i.putu.emk@gmail.com
}

\begin{abstract}
The closeness of the relationship between dogs and human makes the dog can be trained, played together, lived together with human and are invited to socialize with human and other dogs. But, despite its this relationship, the dogs can also have a contagious disease that may be harmful to human. Diagnostic expert system for infectious disease in dogs for as web-based system with the media android used as a tool for diagnosing infectious diseases in dogs based on physical characteristics or symptoms that can be seen or felt without through examination of the specifics. The diagnostics final results are expected to be a reference for further examination and handling of dogs that contract the disease is detected to prevent the disease for humans. This expert system uses a forward chaining inference method and Certainty Factor to infer.
\end{abstract}

Keywords: expert systems, forward chaining, certainty factor

\section{Pendahuluan}

Hewan peliharaan manusia, salah satunya anjing merupakan makhluk sosial yang bisa berinteraksi dengan sesamanya ataupun manusia sehingga tidak sedikit orang memilih anjing sebagai hewan peliharaan. Namun, anjing juga dapat mengidap penyakit menular yang dapat berdampak buruk bagi manusia. Pengaruh penyakit tersebut pada manusia bermacam-macam, dari gatal-gatal, alergi sampai dengan kematian.

Penanganan dini terhadap penyakit menular yang diderita oleh anjing dapat dilakukan untuk mencegah penyakit tersebut semakin parah dan mengurangi resiko penyakit tersebut berdampak buruk bagi manusia. Namun sebelum melakukan penanganan dini, pengetahuan mengenai gejala-gejala dari penyakit menular yang diderita anjing sangat diperlukan karena dapat memprediksi penyakit yang diderita sehingga dapat melakukan penanganan dini yang tepat.

Seiring dengan perkembangan ilmu dan teknologi, terdapat suatu sistem yang dapat membantu dalam pengambilan keputusan. Sistem tersebut adalah Sistem Pakar. Sistem Pakar merupakan sebuah sistem yang menggunakan pengetahuan manusia yang dimasukkan ke dalam komputer untuk memecahkan

\footnotetext{
${ }^{1}$ Alumni Mahasiswa Jurusan Matematika FMIPA Universitas Udayana

${ }^{2,3}$ Staf Pengajar Jurusan Matematika FMIPA Universitas Udayana
} 
masalah-masalah yang biasanya membutuhkan keahlian seorang pakar. Sistem pakar yang baik dirancang agar dapat menyelesaikan suatu permasalahan tertentu dengan meniru kerja dari para ahli (pakar).

Untuk merancang suatu sistem pakar, dapat digunakan teknologi berbasis online yang dikelola melalui sebuah halaman website. Dengan menggunakan data berbasis online, perubahan data pada server dapat langsung dirasakan oleh pengguna sistem yang mengaksesnya. Media yang dipilih dalam penelitian ini adalah android karena merupakan sistem operasi yang dapat ditambahkan aplikasi secara bebas dan terdapat pada beberapa jenis ponsel.

Berdasarkan latar belakang yang telah dipaparkan sebelumnya, penulis ingin membangun suatu sistem pakar berbasis online untuk mendiagnosa penyakit menular pada anjing melalui perangkat android. Dimana hasilnya dapat sebagai penanganan dini terhadap penyakit tersebut dan mengurangi resiko penyakit tersebut dapat berdampak buruk bagi manusia.

\section{Metode Penelitian}

\section{Pelacakan ke Depan (Forward Chaining)}

Forward Chaining adalah sebuah metode pelacakan kedepan, dimana diawali dari fakta-fakta yang diberikan user kemudian dicari dibasis pengetahuan lalu dicari rule yang sesuai dengan fakta-fakta. Setelah itu diadakan hipotesa untuk memperoleh kesimpulan (Kusumadewi [1]).

\section{Pencarian Mendalam Pertama (Depth First Search)}

Depth first search merupakan proses pencarian ke node-node yang selevel. Pencarian dimulai dari node akar ke level yang lebih tinggi. Proses ini diulangi terus hingga ditemukannya solusi (Kusumadewi [1]).

\section{Faktor Kepastian}

Faktor kepastian (certainty factor) diperkenalkan oleh Shortliffe Buchanan dalam pembuatan MYCIN (Widinugraha [2]. Faktor kepastian $(C F)$ merupakan nilai parameter klinis yang diberikan MYCIN untuk menunjukkan besarnya kepercayaan.

Faktor kepastian $(C F)$ didefinisikan sebagai berikut:

$$
C F(H, E)=M B(H, E)-M D(H, E)
$$

dimana:

$\mathrm{CF}\left(\mathrm{H}_{0} \mathrm{E}\right)=$ Certainty factor (faktor kepastian) dari hipotesis $\mathrm{H}$ yang dipengaruhi oleh gejala E. Besarnya CF berkisar antara -1 sampai dengan 1 . Nilai -1 menunjukkan ketidakpercayaan mutlak sedangkan nilai 1 menunjukkan kerpercayaan mutlak.

$M B\left(H_{s} E\right)=$ Measure of belief (tingkat kepercayaan) merupakan ukuran kenaikan kepercayaan terhadap hipotesis $\mathrm{H}$ yang dipengaruhi oleh gejala $\mathrm{E}$ (antara $0-1)$. 
$M D\left(H_{0} E\right)=$ Measure of disbelief (tingkat ketidakpercayaan) merupakan ukuran kenaikan dari ketidakpercayaan terhadap hipotesis $\mathrm{H}$ oleh gejala $\mathrm{E}$ (antara 0-1).

$\mathbb{E} \quad=$ Evidence (peristiwa atau fakta).

Bentuk dasar rumus CF dari kaidah IF E THEN H diberikan sebagai berikut:

$$
C F(H, e)=C F(E, e) \times C F(H, E)
$$

dimana:

$C F(E, e)=$ Faktor kepastian dari fakta $\mathrm{E}$ yang dipengaruhi oleh fakta e.

$C F(H, E)=$ Faktor kepastian dalam hipotesa dengan asumsi bahwa fakta diketahui dengan pasti, yaitu ketika $C F(E, e)=1$.

$C F(H, e)=$ Faktor kepastian hipotesa yang dipengaruhi oleh fakta e.

Jika semua evidence pada antecedent diketahui dengan pasti maka rumusnya akan menjadi:

$$
C F(H, e)=C F(H, E)
$$

\section{PHP (Hypertext Preprocessor)}

PHP (Hypertext Preprocessor) merupakan bahasa pemrograman berbasis web yang memiliki kemampuan untuk memproses data dinamis. PHP banyak digunakan oleh programmer berlatar belakang $\mathrm{C} / \mathrm{C}++$ karena kemiripan syntaxnya. Selain itu PHP juga open source, karenanya gratis dan bebas. Database pasangannya biasanya MySQL, dijalankan bersama webserver.

\section{Java dan Android SDK}

Java adalah sebuah teknologi yang diperkenalkan oleh Sun Microsystems pada pertengahan tahun 1990. Menurut definisi dari Sun, Java adalah nama untuk sekumpulan teknologi untuk membuat dan menjalankan perangkat lunak pada komputer ataupun pada lingkungan jaringan. Java merupakan sebuah teknologi dibanding hanya sebuah bahasa pemrograman, karena Java lebih lengkap dibanding sebuah bahasa pemrograman konvensional.

Android merupakan sistem operasi berbasis Linux untuk ponsel yang meliputi sistem operasi, middleware dan aplikasi kunci yang di release oleh Google. Android menyediakan platform terbuka bagi para pengembang untuk menciptakan aplikasi mereka sendiri untuk digunakan oleh bermacam peranti bergerak. Saat ini disediakan Android SDK (Software Development Kit) sebagai alat bantu dan API diperlukan untuk mulai mengembangkan aplikasi pada platform Android menggunakan bahasa pemrograman Java (Wikipedia [2]). 


\section{Hasil dan Pembahasan}

\section{Identifikasi Masalah dan Pengetahuan}

Masalah-masalah yang diambil dalam pembuatan sistem pakar pendiagnosa penyakit menular pada anjing berdasarkan ciri-ciri fisik atau gejalagejala yang dapat dilihat atau dirasakan tanpa melalui pemeriksaan spesifik.

\section{Pohon Keputusan}

Pohon keputusan merupakan grafik yang akan menjelaskan antara objekobjek yang dihubungkan dengan garis-garis berlabel ("Ya" atau "Tidak"), alasan digunakan pohon keputusan ini adalah karena lebih mudah dipahami. Berikut merupakan contoh pohon keputusan dengan kode penyakit dan gejala untuk sistem pakar pendiagnosa penyakit menular pada anjing yang dibagi berdasarkan penyakit.

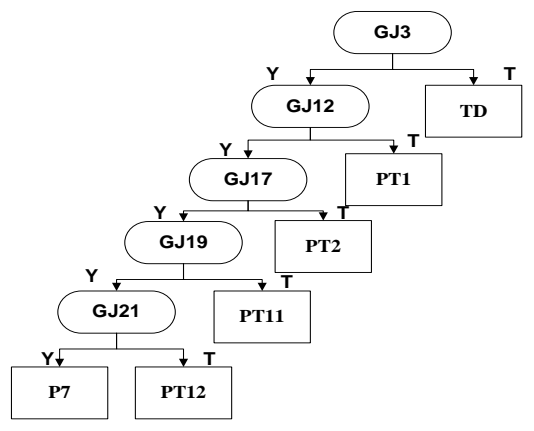

Dimana:

Gambar 1. Pohon Keputusan Penyakit Jamuran (Ringworm)

GJ : Gejala

P : Penyakit

PT : Penyakit tambahan

TD : Tidak ditemukan penyakit

\section{Penerapan Faktor Kepastian}

Faktor kepastian (certaninty factor) dalam hal ini digunakan untuk mengatasi ketidakpastian diagnose penyakit. Penentuan nilai faktor kepastian (CF) dari suatu penyakit yang memiliki gejala-gejala tertentu akan diberikan salah satu contoh kasus dalam menghitung nilai faktor kepastian sebagai berikut:

\section{Rule PT12}

IF gatal

AND bulu rontok

AND terdapat bintik pada permukaan kulit

AND terjadi kerusakan bulu di seluruh muka, hidung atau telinga anjing

THEN Ringworm CF 0,8

OR Flea Allergy Dermatitis CF 0,3

OR Cheyletiella CF 0,3 
Dengan menganggap

$E_{1}$ : Gatal

a. Anjing menggaruk hanya sekali-sekali saja

b. Anjing menggaruk pada bagian tubuh tertentu saja

c. Anjing menggaruk pada bagian-bagian tubuh tertentu terus menerus

d. Anjing menggaruk di seluruh bagian tubuh terus menerus

$E_{2}$ : Bulu rontok

a. Rontok tidak sampai rambut anjing botak

b. Rontok hingga botak dibeberapa bagian tubuh saja

c. Rontok sehingga rambut anjing di seluruh tubuhnya habis

$E_{a}:$ Terdapat bintik pada permukaan kulit

$E_{4}$ : Terjadi kerusakan bulu di seluruh muka, hidung atau telinga anjing

$H_{1}$ : Jamuran (Ringworm)

$H_{2}$ : Peradangan pada kulit karena gigitan kutu (Flea Allergy Dermatitis)

$H_{\mathbb{a}}$ : Peradangan pada kulit akibat adanya parasit pembawa ketombe (Cheyletiella Dermatitis)

Nilai faktor kepastian hipotesa pada saat kejadian (evidence) pasti adalah:

$C F\left(H_{1}, E\right)=C F\left(H_{1}, E_{1} \cap E_{2} \cap E_{a} \cap E_{4}\right)$ $=0,8 \rightarrow$ Nilai sudah ditentukan berdasarkan fakta yang telah ada

yang diberikan oleh pakar.

$$
\begin{aligned}
C F\left(H_{2}, E\right)= & C F\left(H_{2}, E_{1} \cap E_{2} \cap E_{a} \cap E_{4}\right) \\
& =0,3 \\
C F\left(H_{\mathbb{g}^{3}}, E\right)= & C F\left(H_{\mathbb{a}^{3}}, E_{1} \cap E_{2} \cap E_{\mathbb{a}} \cap E_{4}\right) \\
& =0,3
\end{aligned}
$$

Dalam kasus ini, kondisi pasien tidak dapat ditentukan dengan pasti. Nilai kepastian evidence E (Gejala) yang dipengaruhi oleh evidence e (gejala tambahan) ditujukan dengan nilai sebagai berikut:

Misalnya dari pilihan jawaban yang diberikan terdapat beberapa jawaban. Setiap jawaban memiliki bobot masing-masing tergantung dari tingkat keseriusan gejala. Maka user hanya perlu memilih salah satu jawaban saja.

$C F\left(E_{1}, e\right)=0,75$

Anjing menggaruk hanya sekali-sekali saja (CF 0,25)

$\square$ Anjing menggaruk pada bagian tubuh tertentu saja (CF 0,50)

Anjing menggaruk pada bagian-bagian tubuh tertentu terus menerus (CF 0,75)

Anjing menggaruk di seluruh bagian tubuh terus menerus (CF 1)

$C F\left(E_{2}, e\right)=0,67$

$\square$ Rontok tidak sampai rambut anjing botak (CF 0,33)

Rontok hingga botaR dibeberapa bagian tubuh saja (CF 0,67)

Rontok sehingga rambut anjing di seluruh tubuhnya habis (CF 1)

Diasumsikan jawaban

$\mathrm{Ya}=1$ atau Tidak $=0$ 


$$
\left.\begin{array}{l}
C F\left(E_{1}, e\right)=1 \\
C F\left(E_{4}, e\right)=1
\end{array}\right\}
$$

Sehingga

$$
\begin{aligned}
& C F\left(E_{,} e\right)=C F\left(E_{1} \cap E_{2} \cap E_{3} \cap E_{4}, e\right) \\
& =\min \left[C F\left(E_{1}, e\right) \cap\left(E_{2}, e\right) \cap\left(E_{3}, e\right) \cap\left(E_{4}, e\right)\right] \\
& =\min [0,75 ; 0,67 ; 1 ; 1] \\
& =0,67 \\
& \text { Nilai faktor kepastian hipotesa adalah: } \\
& C F\left(H_{1}, e\right)=C F(E, e) \times C F\left(H_{1}, E\right) \\
& =0,67 \times 0,8 \\
& =0,536 \\
& \mathrm{CF}\left(\mathrm{H}_{2}, e\right)=\mathrm{CF}\left(\mathrm{E}_{2}, \mathrm{e}\right) \times \mathrm{CF}\left(\mathrm{H}_{2}, \mathrm{E}\right) \\
& =0,67 \times 0,3 \\
& =0,201 \\
& C F\left(H_{3}, e\right)=C F\left(E_{3} e\right) \times C F\left(H_{3}, E\right) \\
& =0,67 \times 0,3 \\
& =0,201
\end{aligned}
$$

Maka besar kepercayaan anjing yang didiagnosa menderita penyakit Jamuran (Ringworm) sebesar 53,6\% atau Peradangan pada kulit karena gigitan kutu (Flea Allergy Dermatitis) sebesar 20,1\% atau Peradangan pada kulit akibat adanya parasit pembawa ketombe (Cheyletiella Dermatitis) sebesar 20,1\%.

\section{Pengujian Sistem}

Tahap pengujian sistem merupakan tahap uji coba untuk menguji keakuratan dari sistem pakar yang dibuat, yaitu dengan melakukan perbandingan antara hasil dari diagnosa sistem pakar dengan kebenaran aturan yang telah dirancang. Pengujian dilakukan sesuai dengan contoh kasus rule PT12.

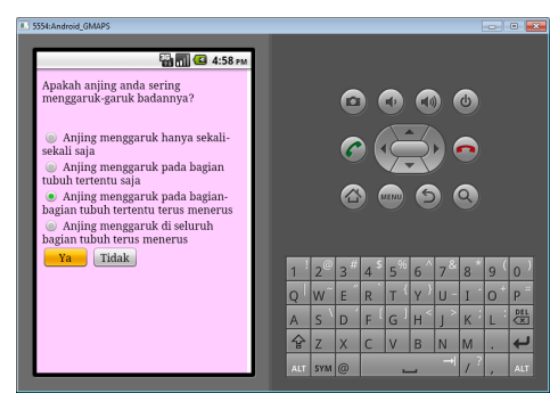

Gambar 2. Menu Pertanyaan

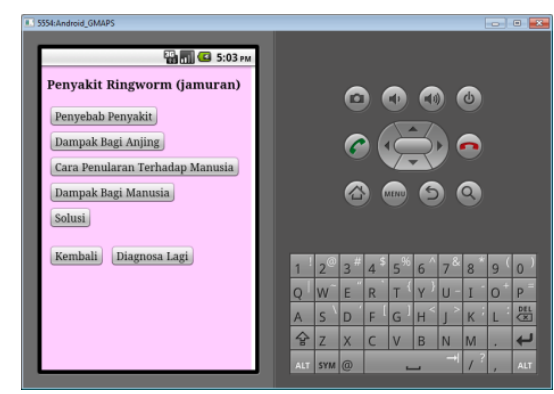

Gambar 4. Menu Penyakit

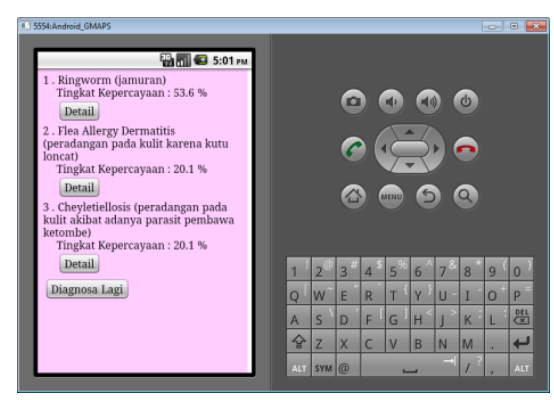

Gambar 3. Menu Hasil Diagnosa

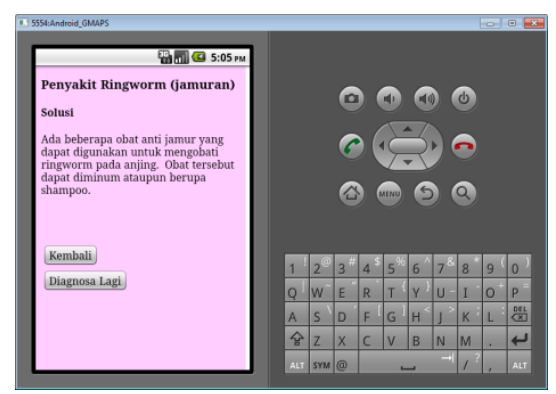

Gambar 5. Menu Solusi 


\section{Kesimpulan}

Dari penelitian ini dapat diperoleh beberapa simpulan sebagai berikut: (1) Sistem pakar pendiagnosa penyakit menular pada anjing melalui perangkat android telah dapat dibangun dan dapat mendiagnosa penyakit berdasarkan gejala yang dialami oleh pasien (anjing); (2) Sistem pakar yang dibuat telah dapat memuat kesimpulan akhir yang lebih dari satu (multi output) dengan mengelompokkan penyakit-penyakit yang memiliki satu atau lebih gejala yang sama; dan (3) Sistem pakar dapat mengetahui besar tingkat kepercayaan dari penyakit yang didiagnosa dengan menggunakan rumus faktor kepastian (Certainty Factor).

\section{Daftar Pustaka}

[1] Kusumadewi, S. (2003) Artificial Intelligence (Teknik dan Aplikasinya), $1^{\text {st }}$ edition, Yogyakarta: Penerbit Graha Ilmu.

[2] Wikipedia (2011) Android (Sistem Operasi), [Online], Available: HYPERLINK "http://id.wikipedia.org/wiki/Android_(sistem_operasi)" http://id.wikipedia.org/wiki/Android_(sistem_operasi) [18 Apr 2012].

[3] Winigraha, M.A. (2008) Sistem Pakar Pendiagnosa Penyakit dengan Gejala Utama Demam (Skripsi), Bukit Jimbaran: Jurusan Matematika Fakultas Matematika dan Ilmu Pengetahuan Alam Universitas Udayana. 